\title{
Comparative efficacy of four insecticides and two indigenous plant extracts against wild crucifer aphid, Lipaphis erysimi (Hemiptera: Aphididae)
}

\author{
Habib-ur-Rehman ${ }^{1 *}$, Qurban Ali ${ }^{2}$, Amer Rasul ${ }^{1}$, Muhammad Sagheer ${ }^{1}$, \\ Beenish Majeed ${ }^{3}$ and Muhammad Aslam Farooqi ${ }^{4}$ \\ 1. Department of Entomology, University of Agriculture, Faisalabad-Pakistan \\ 2. Entomological Research Institute, Ayub Agricultural Research Institute, Faisalabad-Pakistan \\ 3. Department of Chemistry, Government College University, Faisalabad-Pakistan \\ 4. Department of Entomology, University College of Agriculture \& Environmental Sciences The Islamia University \\ of Bahawalpur-Pakistan \\ *Corresponding author's email: habib.ento@gmail.com \\ Citation \\ Habib-ur-Rehman, Qurban Ali, Amer Rasul, Muhammad Sagheer, Beenish Majeed and Muhammad Aslam Farooqi. \\ Comparative efficacy of four insecticides and two indigenous plant extracts against wild crucifer aphid, Lipaphis \\ erysimi (Hemiptera: Aphididae). Pure and Applied Biology. Vol. 9, Issue 3, pp1773-1779. \\ http://dx.doi.org/10.19045/bspab.2020.90188
}

Received: 20/01/2020

Revised: $22 / 03 / 2020$ Accepted: $10 / 04 / 2020$

Online First: $20 / 04 / 2020$

\section{Abstract}

Gold-of-pleasure, leindotter and linseed dodder are the titles used for Camelina sativa L. This crop is under menace of severe infestation of aphid. Aphid population of was noted from arbitrarily five selected camelina plants of every treatment. Two plant oils (Ricinus communis, Jatropha curcus) and four synthetic insecticides (Acetamiprid, Imidachloprid, Cypermethrin and Diafenthiuron) were used. Mortality data of L. erysimi was recorded at regular interval of 24 hs. till 96 hs. of treatments applications. Results of toxicity bioassays displayed that application of Acetamiprid and $R$. communis resulted in enhanced mortality of L. erysimi than the other treatments, applied. Highest mortality rate $(78.67 \%)$ of the test insect pest was recorded in Canadian variety of camelina by application of Acetamiprid whilst lowest $36.10 \%$ was observed by Diafenthiuron, after exposure period of $96 \mathrm{hs}$. While highest and lowest mortality rates of the target insect pest in Australian camelina were $70.19 \%$ and $29.10 \%$, respectively. Consequently, it is concluded that the application of Acetamiprid can be an effective tool in integrated pest management programme.

Keywords: Infestation; Integrated pest management; Mortality; Treatment and varieties

\section{Introduction}

There is shortage of vegetable oil production in Pakistan and current native oil resources fulfill on $28 \%$ of the country needs. In order to meet the shortage, $75 \%$ is being imported [1]. The budget for imported comestible oils is rising into billions of dollars; becoming a huge drain on our external exchange reserves. During 2006-2007, import of oilseeds and edible oil cost of US\$ 1045 million. Requirement for edible oil stood at 3.094 million tons (MT) in the similar year [2]. Several factors can be ascribed to the low production like change of cropping 
preference, reduction of area under oil seed crop, old cultural practices [3], nonavailability of better-quality seeds, attacks of diseases and insect pests [4]. The feeding behaviors and consequent sternness of these insect pests differs in diverse agro-ecological situations. A huge number of oleaginous crops are cultivated in several areas (like Faisalabad, Sahiwal, Multan etc. and in some areas of Sindh as well) of Pakistan; nevertheless the quantity of edible oil is not adequate to fulfill our requirements [5]. Therefore, we have to import a huge quantity of comestible oil 143.5 million tones (MT) from foreign countries. Therefore, a massive quantity of foreign exchange i.e. 19044.8 million rupees is spend to import the comestible oil [6]. In the years 2009-2010, comestible oil yield was around 1.749 (MT) in Pakistan. Growing request of edible oil, variations in national yield and nonstop upsurge in the imports are the dominant features of current comestible oil condition in the Pakistan [7]. In 2018-19 (July-March), 2.421 (MT) edible oil was imported. Local production of edible oil during this period recorded at 0.500 million tons [8].

Camelina sativa seeds have $28-40 \%$ of vegetable oil, which is tremendously better to that normally present in soybean (18-22\%) [7]. Two varieties of camelina crop are usually grown for the purpose of edible oil; spring variety (Camelina sativa $\mathrm{L}$. Crantz) and winter camelina (Camelina silvestris Wallr) whereas spring variety of Camelina is known as the best for biodiesel. The fruit and seed length of $C$. sativa is greater compared to $C$. silvestris [9]. Camelina crop cultivation is amplified owing to its little requirements of agronomic inputs and greater potential for biodiesel production [10]. C. sativa is a spring annual oilseed and broad leaf crop that can be grown well in moderate climates. Contrasting to other usually cultivated oilseed crops such as sunflower, soybean, rapeseed and canola, $C$. sativa does not need ample fertilizer, water and pesticide. The average produce of the crop ranged from 420$640 \mathrm{~L} / \mathrm{ha}$ whereas contents of fiber and protein in camelina crop are similar to that of soybean meal [11]. As camelina is comparatively a foreign crop, vulnerability to different diseases and insect pests is not well understood. Many species of insect pests like cabbage seed pod weevil, flea beetle and aphid that normally distress canola has not been detected in camelina crop [11, 12]. $C$. sativa has an elevated level of resistance to flea beetle attack as described by many researchers [13-15]. Unluckily, this crop in a great menace of severe infestation of aphid in Pakistan. Camelina crop is recently familiarized in Pakistan and low numbers of insect pests have been noticed that result in severe harm to canola crop [16]. Lipaphis erysimi (Kalt.) is known to be the most severe insect pest amongst these insect pests, which is accountable for a substantial yield loss ranging in $35.4-96 \%$ depending upon growing seasons. Young ones and adults of aphid contribute meaningfully to damage through feeding on the plant and frequently casing the whole surface of pods, shoots and flower buds [17]. For the management of $L$. erysimi, effective entomocidal chemicals must be practiced at suitable dosages. Numerous investigators have examined effectiveness of many insecticides including thiamethoxam, diafenthiuron and acetamiprid against turnip aphid, L. erysimi [16]. Mustard crop can perform a significant part in accomplishing the needs of edible oil if it is cultivated on large scale and suitable managing approaches are practiced for the aphid control. Therefore, the present investigation was concentrated to assess the effectiveness of Ricinus communis, Jatropha curcus, Cypermethrin, Imidachloprid, Acetamiprid and Diafenthiuron against $L$. erysimi in the both varieties of camelina.

\section{Materials and methods}


The research work has been carried out on two varieties of camelina (Australian and Canadian) sown in November 2018 at field area of University of Agriculture, Faisalabad, Pakistan by hand-driven drill technique at a seed rate of $5 \mathrm{~kg}$ per hectare. Standard cultural practices were followed. The research trial was laid out in a Randomized Complete Block Design having four replicates. Camelina crop was monitored from germination to maturity for recording insect pests. Insect pests populations have been noted after regular intervals of seven days. $L$. erysimi was detected as the main insect pest.
Population of aphid was documented from arbitrarily chosen five plants of every treatment. The sampling technique of $L$. erysimi was identical as described by [18]. The insecticides and their recommended dose rates are mentioned in (Table 1). Water was used as control.

All the insecticides were sprayed using knapsack sprayer (hand operated) with a hollow cone nozzle (KB-5C, Korea). The volume of sprayer tank was $5 \mathrm{~L}$ using work pressure of 1-2 bar. The mortality findings were noted afterward regular intervals of 24 hs. till 96 hs. of the treatment application.

Table 1. List of different treatments and recommended dose rates

\begin{tabular}{|c|c|c|c|c|}
\hline Treatments & Common Names & Brand/Scientific names & Formulations & Dose/acre \\
\hline $\mathrm{T}_{1}$ & Acetamiprid & Rani & $20 \% \mathrm{SP}$ & $50 \mathrm{~g}$ \\
\hline $\mathrm{T}_{2}$ & Imidachloprid & Confidor & $20 \% \mathrm{SL}$ & $250 \mathrm{ml}$ \\
\hline $\mathrm{T}_{3}$ & Cypermethrin & Mustang & $10 \mathrm{EC}$ & $250 \mathrm{ml}$ \\
\hline $\mathrm{T}_{4}$ & Diafenthiuron & Polo & $50 \% \mathrm{SC}$ & $200 \mathrm{ml}$ \\
\hline $\mathrm{T}_{5}$ & Castor bean & Ricinus communis & Liquid & - \\
\hline $\mathrm{T}_{6}$ & Jatropha oil & Jatropha curcus & Liquid & - \\
\hline $\mathrm{T}_{7}$ & water & Control & Liquid & - \\
\hline
\end{tabular}

\section{Statistical analysis}

The collected data was subjected to Abbott's formula for calculation of mean percent mortality and then data were subjected to STATISTICA 8.1 software package

[19] Means of treatments have been compared by Tuckey's HSD test at probability $(\mathrm{P}=0.005)$. $\quad \mathrm{LC}_{50}$ has been calculated using Probit-analysis.

\section{Results}

Findings of (Table 2) displayed that use of $R$. communis and Acetamiprid caused higher mortality of L. erysimi compared to other treatments, used. Mortality of the target insect pest was 78.67, 72.19, 58.17, 51.24, 45.76 and $36.10 \%$ in Canadian variety of camelina by application of Acetamiprid, $R$. communis, J. curcus, Cypermethrin,
Imidachloprid and Diafenthiuron, correspondingly after exposure period of 96 (hs.). While mortality values of the target insect pest in Australian camelina were $70.19,67.56,54.17,49.62,41.35$, and 29.10 $\%$, respectively after longest exposure period (96 hs.). Control was least effective as no mortality was recorded in control experimental blocks.

Acetamiprid displayed relatively more toxicity with $\mathrm{LC}_{50}$ value of $12.380 \mathrm{~g} \mathrm{ml}^{-1}$ followed by Ricinus communis and Jatropha curcus with values of 19.042 and $30.157 \mathrm{~g}$ $\mathrm{ml}^{-1}$, correspondingly. Overall all the tested insecticidal chemicals performed better than control but acetamiprid was the most toxic (Table 3). 
Table 2. Toxic impacts of different treatments (plants oils and synthetic insecticides) against Lipaphis erysimi

\begin{tabular}{|c|c|c|c|c|}
\hline Treatments & 24 hs. & 48 hs. & 72 hs. & 96 hs. \\
\hline \multicolumn{5}{|c|}{ Australian variety } \\
\hline Acetamiprid & $38.23 \pm 1.30 \mathrm{a}$ & $43.56 \pm 3.10 \mathrm{a}$ & $55.23 \pm 2.70 \mathrm{a}$ & $70.19 \pm 3.20 \mathrm{a}$ \\
\hline Ricinus communis & $34.10 \pm 2.07 \mathrm{~b}$ & $39.26 \pm 3.04 \mathrm{c}$ & $50.74 \pm 1.10 \mathrm{~b}$ & $67.56 \pm 2.78 \mathrm{ab}$ \\
\hline Jatropha curcus & $29.35 \pm 3.09 c$ & $40.04 \pm 2.56 \mathrm{ab}$ & $45.14 \pm 2.44 \mathrm{c}$ & $54.17 \pm 1.11 \mathrm{~b}$ \\
\hline Cypermethrin & $18.10 \pm 1.10 \mathrm{~d}$ & $25.12 \pm 3.11 \mathrm{~d}$ & $41.20 \pm 3.11 \mathrm{~d}$ & $49.62 \pm 2.10 \mathrm{c}$ \\
\hline Imidachloprid & $15.10 \pm 2.34 \mathrm{de}$ & $21.35 \pm 1.00 \mathrm{e}$ & $37.16 \pm 1.11 \mathrm{e}$ & $41.35 \pm 2.0 \mathrm{~d}$ \\
\hline Diafenthiuron & $12.34 \pm 2.10 \mathrm{de}$ & $17.11 \pm 3.10 \mathrm{f}$ & $24.30 \pm 3.23 \mathrm{f}$ & $29.10 \pm 3.10 \mathrm{e}$ \\
\hline \multicolumn{5}{|c|}{ Canadian variety } \\
\hline Acetamiprid & $45.15 \pm 2.30 \mathrm{a}$ & $56.04 \pm 2.01 \mathrm{a}$ & $67.19 \pm 3.20 \mathrm{a}$ & $78.67 \pm 3.20 \mathrm{a}$ \\
\hline Ricinus communis & $41.21 \pm 2.87 \mathrm{ab}$ & $44.04 \pm 1.92 \mathrm{~b}$ & $59.19 \pm 2.78 b$ & $72.19 \pm 2.78 b$ \\
\hline Jatropha curcus & $34.14 \pm 1.46 \mathrm{c}$ & $41.53 \pm 1.11 \mathrm{~b}$ & $48.17 \pm 1.11 \mathrm{c}$ & $58.17 \pm 1.11 \mathrm{c}$ \\
\hline Cypermethrin & $28.35 \pm 3.27 \mathrm{~d}$ & $37.15 \pm 3.10 b c$ & $46.35 \pm 2.10 \mathrm{c}$ & $51.24 \pm 2.10 \mathrm{~d}$ \\
\hline Imidachloprid & $23.20 \pm 2.14 \mathrm{e}$ & $29.35 \pm 3.07 \mathrm{~d}$ & $40.41 \pm 2.0 \mathrm{~d}$ & $45.76 \pm 2.0 \mathrm{e}$ \\
\hline Diafenthiuron & $18.02 \pm 1.3 \mathrm{f}$ & $21.35 \pm 2.56 \mathrm{e}$ & $27.35 \pm 3.10 \mathrm{e}$ & $36.10 \pm 2.10 \mathrm{f}$ \\
\hline
\end{tabular}

Table 3. LC50-values

\begin{tabular}{|c|c|c|c|c|c|c|c|c|}
\hline \multirow{2}{*}{ Treatments } & \multirow{2}{*}{$\begin{array}{c}\text { Exposure } \\
\text { period } \\
\text { (hs) }\end{array}$} & \multirow{2}{*}{ Slope } & \multirow{2}{*}{$\begin{array}{c}Z \text { Z- } \\
\text { value }\end{array}$} & \multirow{2}{*}{$\begin{array}{c}\text { P- } \\
\text { value }\end{array}$} & \multirow{2}{*}{$\begin{array}{c}\mathbf{R}^{2}- \\
\text { value }\end{array}$} & \multirow{2}{*}{$\begin{array}{c}\mathbf{L C}_{50} \\
\text { (value) } \\
\left(\mathrm{g} \mathrm{ml}^{-1}\right)\end{array}$} & \multicolumn{2}{|c|}{$\begin{array}{c}\text { Fiducial limit } \\
(95.0 \%)\end{array}$} \\
\hline & & & & & & & Lower & Upper \\
\hline \multirow{4}{*}{ Acetamiprid } & 24 & 6.3 & 2.13 & 0.028 & 0.897 & 58.239 & 25.73 & 92.56 \\
\hline & 48 & 5.4 & 2.01 & 0.040 & 0.915 & 40.017 & 16.93 & 81.10 \\
\hline & 72 & 10.1 & 3.56 & 0.001 & 0.941 & 29.380 & 13.60 & 36.40 \\
\hline & 96 & 12.4 & 3.56 & 0.001 & 0.921 & 12.380 & 10.60 & 25.07 \\
\hline \multirow{4}{*}{$\begin{array}{l}\text { Ricinus } \\
\text { communis }\end{array}$} & 24 & 7.1 & 2.63 & 0.002 & 0.982 & 34.251 & 22.95 & 94.21 \\
\hline & 48 & 8.4 & 2.49 & 0.021 & 0.940 & 30.770 & 27.35 & 62.72 \\
\hline & 72 & 14.5 & 2.61 & 0.008 & 0.913 & 21.042 & 29.60 & 45.04 \\
\hline & 96 & 15.2 & 3.81 & 0.006 & 0.913 & 19.042 & 13.60 & 29.04 \\
\hline \multirow{4}{*}{$\begin{array}{c}\text { Jatropha } \\
\text { curcus }\end{array}$} & 24 & 9.8 & 2.72 & 0.032 & 0.988 & 38.367 & 25.01 & 87.34 \\
\hline & 48 & 7.2 & 2.44 & 0.027 & 0.903 & 34.420 & 22.79 & 62.30 \\
\hline & 72 & 10.4 & 2.21 & 0.031 & 0.945 & 30.157 & 24.54 & 58.19 \\
\hline & 96 & 17.0 & 3.23 & 0.015 & 0.926 & 28.941 & 20.40 & 56.13 \\
\hline \multirow{4}{*}{ Imidachloprid } & 24 & 5.7 & 2.48 & 0.019 & 0.950 & 41.670 & 23.45 & 94.67 \\
\hline & 48 & 6.3 & 2.42 & 0.124 & 0.972 & 38.134 & 37.72 & 108.90 \\
\hline & 72 & 4.9 & 2.38 & 0.030 & 0.969 & 36.121 & 23.76 & 86.51 \\
\hline & 96 & 16.2 & 2.29 & 0.028 & 0.965 & 35.170 & 20.33 & 76.32 \\
\hline \multirow{4}{*}{ Diafenthiuron } & 24 & 4.7 & 1.57 & 0.137 & 0.989 & 146.603 & 91.07 & 214.90 \\
\hline & 48 & 5.5 & 1.49 & 0.107 & 0.938 & 124.105 & 82.67 & 208.45 \\
\hline & 72 & 17.0 & 2.85 & 0.001 & 0.986 & 42.613 & 22.01 & 74.10 \\
\hline & 96 & 18.5 & 3.02 & 0.001 & 0.987 & 44.654 & 18.01 & 76.18 \\
\hline
\end{tabular}

In (Fig. 1) data showed that relative higher aphid population was recorded on Canadian variety of camelina than the Australian variety in all the three experimental blocks before the treatments applications. 


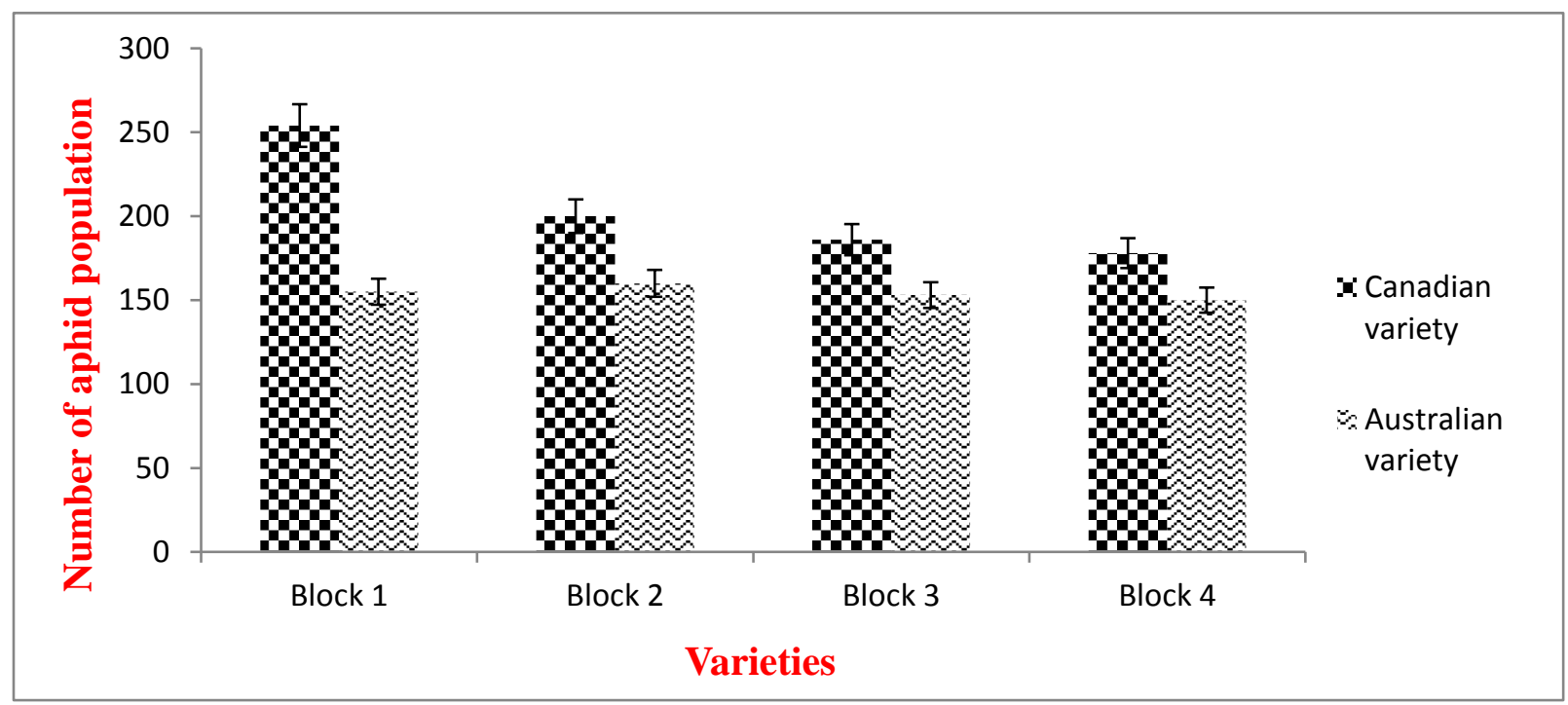

Figure 1. Mean population of the aphid on two varieties of camelina crop under study

\section{Discussion}

Camelina sativa is an oil seed crop which belongs to family Brassicaceae that comprises of numerous plant species. The findings of the current study specified that the aphid is one of the severe insect pests of $C$. sativa crop in Pakistan. However, the variation between L. erysimi populations on both camelina varieties might be owing to vegetative features of the plant. There is very restricted research work found on Australian camelina, though there is likelihood that host plant resistance mechanisms may be cause non-preference of L. erysimi to this crop [18, 20]. There is difference in leaf morphologies of both varieties of camelina crop. The leaves of Canadian camelina are only superficially serrated but of Australian camelina are extremely saw-liked and greater leaf area index as compared to Canadian camelina. Leaves of Australian camelina are hairier as compared to Canadian camelina [21]. As far as the Chemical control is concerned, it yet remains key management tool of insect pest control and is also important in the notion of Integrated Pest Management (IPM). Results of toxicity bioassays reflected that $R$. communis oil and acetamiprid were relatively greater effective chemicals than that of $J$. curcus, Cypermethrin, Imidachloprid and Diafenthiuron. Average mortality rate after 96 hs has been noted as 78.67, 72.19, 58.17, $51.24,45.76,36.10 \%$ in Canadian variety and $70.19,67.56,54.17,49.62,41.35,29.10 \%$ in Australian camelina. Among the all treatments, Acetamiprid was the most operative insecticide in the varieties of $C$. sativa, being revealed in our study.

The results of current research displayed that acetamiprid executed best in decreasing $L$. erysimi population on camelina crop trailed by Ricinus communis, J. curcus, Cypermethrin, Imidachloprid and Diafenthiuron nevertheless their efficacy nearly parallel to each other. Yet, acetamiprid executed best in decreasing the aphid population on both camelina varieties. The outcomes of presented research work are extremely concurring with [22] in which they applied thiamethoxam, diafenthiuron and acetamiprid for the control of aphid population. The findings of their experimentations reflected that acetamiprid was the most operative as compared to diafenthiuron, thiamethoxam in controlling of aphid populations. Outcomes of our 
experiment are in agreement with the results of [16] who checked the effectiveness of some insecticides against Phyllotreta spp.) on Indian mustard. Acetamiprid (125 g/ha) showed as the most effective insecticide trailed by acephate, oxydemeton, profenofos, imidacloprid, dimethoate, thiamethoxam and methyl for the control of aphids. [23] tested the effectiveness of 5 insecticides viz., Lannate 40SP (methomyl), Advantage 20 EC (carbosulfan), Mospilan 20SP (acetamiprid), Confidor 200 SL (imidacloprid) and Actara 25 WP (thiomethoxan) for the control of aphid. The findings displayed that imidacloprid and acetamiprid provided best outcomes against aphid. Our findings also support the results from many researchers that acetamiprid was very effective against various insect pests.

The information regarding growth of insecticidal resistance against traditional insecticides has raised stern anxieties concerning to their effectiveness in the field. Nonetheless, the neonicotinoids as acetamiprid and imidacloprid proved extremely operative for farmers owing to altered way of action than to the former insecticides. Acetamiprid be in the accurate place to second generation of the nicotinoids. Being systemic insecticide, it has translaminar activity and both contact as well as stomach mode of actions. Its foliar spray is very operative for the control of aphid populations than that of other insecticides. Owing to their mode of action, there is no or little cross-resistance to earlier developed insecticides like chlorinated hydrocarbons, carbamates, organophosphates, and pyrethroids. Currently, Neonicotinoids are substituting earlier insecticides for the effective control of many major crops insect pests [24].

\section{Conclusion}

Outcomes of the toxicity bioassays disclosed that amount all the treatment used. However, oil of $R$. communis oil and acetamiprid were the most operative entomocidal candidate to control the population of $L$. erysimi. Exposure period was important as comparative greater mortality of the aphid was achieved after longest exposure period (i.e. 96 hrs.). Hence, use of $R$. communis oil and acetamiprid are suggested as perfect and effective chemicals for the integrated pests management of aphid populations on camelina crop.

\section{Authors' contributions}

Conceived and designed the experiments: $\mathrm{H}$ Rehman \& A Rasul, Performed the experiments: H Rehman, Q Ali \& B Majeed, Analyzed the data: M Sagheer \& MA Farooqi, Contributed materials/ analysis/ tools: B Majeed \& MA Farooqi, Wrote the paper: H Rehman.

\section{Acknowledgements}

The authors acknowledge the department of Entomology, University of Agriculture, Faisalabad for accomplishment of the research work

\section{References}

1. Zaidi SMH (2014). Edible Oil Imports in Pakistan. South Asian J Manag Sci 8(1): 18.

2. Anonymous (2007-2008). Agricultural statistics of Pakistan. Ministry of Food, Agriculture \& Livestock; Islamabad (Pakistan).

3. Kassam A, Friedrich T, Shaxson F, \& Pretty J (2009). The spread of conservation agriculture: Justification, sustainability and uptake. Int J Agric Sustain 7: 292-320.

4. Mahmood T, Hassan E, Ali M, \& Hussain M (2012). Faisal canola: A new high yielding canola variety for general cultivation in Punjab. J Agric Res 50: 321328.

5. Razaq M, Abbas G, Farooq M, Aslam M, \& Athar HR (2014). Effect of insecticidal application on aphid population, photosynthetic parameters and yield components of late sown varieties of canola, Brassica napus L. Pak J Zool 46: 661-668. 
6. Sarwar M, Ahmad M, Siddique QH, Rajput AA, \& Toufiq M (2003). Efficiency of different chemicals on canola strain rainbow for aphid control. Asia J Pl Sci 2: 831-833.

7. GOP (2010). Economic survey of Pakistan, 2009-2010. Ministry of Food, Agriculture \& Livestock; Islamabad (Pakistan).

8. GOP (2019). Economic survey of Pakistan, 2018-19. Ministry of Food, Agriculture \& Livestock Islamabad (Pakistan).

9. Francis A, \& Warwick SI (2009). The biology of Canadian weeds and Camelina alyssum (Mill.) Thell., C. microcarpa Andrz. C. sativa (L.). Crantz Can Pl Sci 89: 791-810.

10. Gugel RK, \& Falk SG (2006). Agronomic and seed quality evaluation of Camelina sativa in western Canada. Med Cannabis Cannabinoids 1: 96-103.

11. Dober P, \& Jurcone S (2011). Camelina sativa-an oilseed crop with unique agronomic characteristic. Univ Agron Sci Vet Med Bucharest LIV: 425-430.

12. Moser BR, \& Vaughn SF (2010). Evaluation of alkyl esters from Camelina sativa oil as biodiesel and as blend components in ultra-low-sulfur diesel fuel. Bioresour Tech 101: 646-653.

13. Waraich EA, Ahmed Z, Ahmad R, \& Shabbir RN (2008). Modulating the phenology and yield of camelina sativa $\mathrm{L}$. by varying sowing dates under water deficit stress conditions. Soil Environ 36: 84-92.

14. Pachagounder P, Lamb RJ, \& Bodnaryk RP (1998). Resistance to the flea beetle Phyllotreta cruciferae (Coleoptera: Chrysomelidae) in false flax, Camelina sativa (Brassicaceae). Can Entomol 130: 235-240.

15. Soroka J, R Gugel, R Elliott, G Rakow \& JP Raney (2003). Resistance of crucifer species to insect pests. Proc. GCIRC. $11^{\text {th }}$ Inter. Rapeseed Congr., 3:1031-1033.

16. Dosdall LM, \& Stevenson FC (2005). Managing flea beetle (Phyllotreta spp.) (Coleoptera: Chrysomelidae) in Canada with seeding date, plant density, and seed treatment. Am Soc Agron 97: 1570-1578.

17. Dhaka SS, Gaje S, Siarwa MYP, \& Anil K (2009). Efficacy of new insecticides against mustard aphid, Lipaphis erysimi (Kalt.). J Oilseed Res 26: 172.

18. Martinelli T, \& Galasso I (2011). Phenological growth stages of Camelina sativa according to the extended $\mathrm{BBCH}$ scale. Annals Appl Biol 158(1): 87-94.

19. Abbot WS (1925). A method of comparing the effectiveness of an insecticide. J Econ Entomol 18: 265-267.

20. Chattopadhyay C, Agrawal R, Kumar A, Singh YP, Roy SK, Khan SA, Bhar LM, Chakravarthy NVK, Srivastava, PBS, Singh B, \& Mehta SC (2005). Forecasting of Lipaphis erysimi on oilseed Brassicas in India. Crop Prot 24: 1024-1053.

21. Moser BR (2010). Camelina (Camelina sativa L.) oil as a biofuels feedstock: Golden opportunity or false hope?. Lipid Technol 22: 270-273.

22. Patil S, Sridevi D, Babu TR, \& Pushpavathi B (2018). Field efficacy of selected insecticides against cowpea aphid, Aphis craccivora (Koch). J Entomol Zool Stud 11: 228-231.

23. Farooq A, \& Tasawar Z (2009). Comparative efficacy of five different insecticides against Brevicoryne brassicae (Linn.) (Homoptera: Aphididae), a pest on canola in Southern Punjab, Pakistan. PakJ Zool 41: 79-81.

24. Jactela $H$, Verheggenb $F$, Thiéryc $D$, Escobar-Gutiérrezd AJ, Gachete E, \& Desneuxf N (2019). Alternatives to neonicotinoids. Environ Int 129: 423-429. 